\title{
DOS FILÓSOFOS GREGOS À BOHR: UMA REVISÃO HISTÓRICA SOBRE A EVOLUÇÃO DOS MODELOS ATÔMICO.
}

Bruno Elias Rocha Lopes ${ }^{1}$

Beatriz Machado Gomes ${ }^{2}$

\begin{abstract}
RESUMO
O entendimento sobre do que é formada a matéria gera fascínio e curiosidade desde o início do estudo do mundo natural, sendo essa ideia objeto de estudo de vários cientistas e pensadores ao longo da história da humanidade. A compreensão da partícula formadora da matéria e o seu comportamento vem sendo estudada e reformulada ao longo da história da ciência, sendo estudado desde o início do pensamento científico, através dos gregos, passando pelos estudos da alquimia na idade média, até os séculos XIX e XX com a retomada da visão corpuscular da matéria sendo aprimorada pelo modelo de Rutherford-Bohr.
\end{abstract}

Palavras-chave: Átomo, História da Ciência, História da Química

\section{FROM GREEK PHILOSOPHERS TO BOHR: A HISTORICAL REVIEW ON THE EVOLUTION OF ATOMIC MODELS.}

\begin{abstract}
The understanding of what constitutes matter generates fascination and curiosity from the beginning of the study of the natural world, being this idea object of study of several scientists and thinkers throughout the history of humanity. The understanding of the particle forming the matter and its behavior has been studied and reformulated throughout the history of science, being studied from the beginning of scientific thought, through the Greeks, and the studies of alchemy in the middle ages until the XIX and XX centuries with the resumption of corpuscular vision of the matter being improved by the Rutherford-Bohr model.
\end{abstract}

Keywords: Atom, History of Science, History of Chemistry

${ }^{1}$ Faculdade São Paulo- FSP, ${ }^{1}$ Rede pública de Ensino do estado de Rondônia

2Universidade Federal de Rondônia - Unir

*Autor para correspondência: brunoerl@gmail.com

Manuscrito submetido em: $11 / 07 / 2018$

Aceito para publicação em: $20 / 12$ / 2018

Revista Ifes Ciência, v.4, n.2, 2018 - Instituto Federal do Espírito Santo 


\section{INTRODUÇÃO}

Os modelos atômicos são representações baseadas em experimentos e procuram explicar a forma e o comportamento do que seria um átomo na realidade. São elaborados com a finalidade de elucidar os fenômenos que acontecem na natureza. Como até então não existe uma tecnologia que permite a visualização de um átomo real, os modelos possuem um papel de grande importância, ou seja, de possibilitar uma visão mais próxima o possível do que seria na realidade. Esses modelos foram evoluindo em sua complexidade, conforme avançava-se o conhecimento cientifico, o que propiciava a elaboração de teorias mais elegantes e, logicamente, mais complexas e tangíveis para a compreensão da matéria e dos fenômenos que a cercam.

\section{DOS FILÓSOFOS GREGOS AO MODELO DE DALTON.}

Os primeiros relatos de descrição sobre o que forma a matéria e entendimento dos fenômenos naturais, de forma desconectada de qualquer crença religiosa ou fenômenos sobrenaturais e paranormais, datam a partir dos filósofos gregos no século $\mathrm{V}$ a.C, onde existiam visões diferentes sobre esse tema. Thales de Mileto, pensava que a água era a base da constituição de tudo; Anaxímenes, o qual dizia que o principal elemento constituindo o universo era o ar; e Heráclito, que dizia que o fogo era o elemento principal, pois ele transformava tudo o que tocava (ASIMOV, 1965). Uma delas foi elaborada por Empédocles, que estabeleceu que toda a matéria era formada pelos quatro elementos (fogo, terra, água e ar), contudo a diferença na quantidade desses elementos presentes nas substâncias formaria matérias diferentes possuindo uma simbologia própria para representar cada um desses elementos (PEDUZZI, 2005).

Esse conceito de formação da matéria foi posteriormente refinado e aperfeiçoado por Aristóteles, por volta do ano de 350 a.C., associando "qualidades" (quente ou frio, seco ou úmido) a cada um dos elementos, sendo que a diferença entre eles estaria relacionada com essas qualidades, se elas seriam semelhantes ou opostas. A interpretação que se dá a ideia de Empédocles a partir da visão de Aristóteles é que o Ar seria quente e úmido, a Água fria e úmida, o Fogo quente e seco e a Terra seria fria e seca (Figura 1), sendo que a transformação de um elemento em outro dependeria da inversão dessas qualidades, trocando uma pela outra (ASIMOV, 1965). 


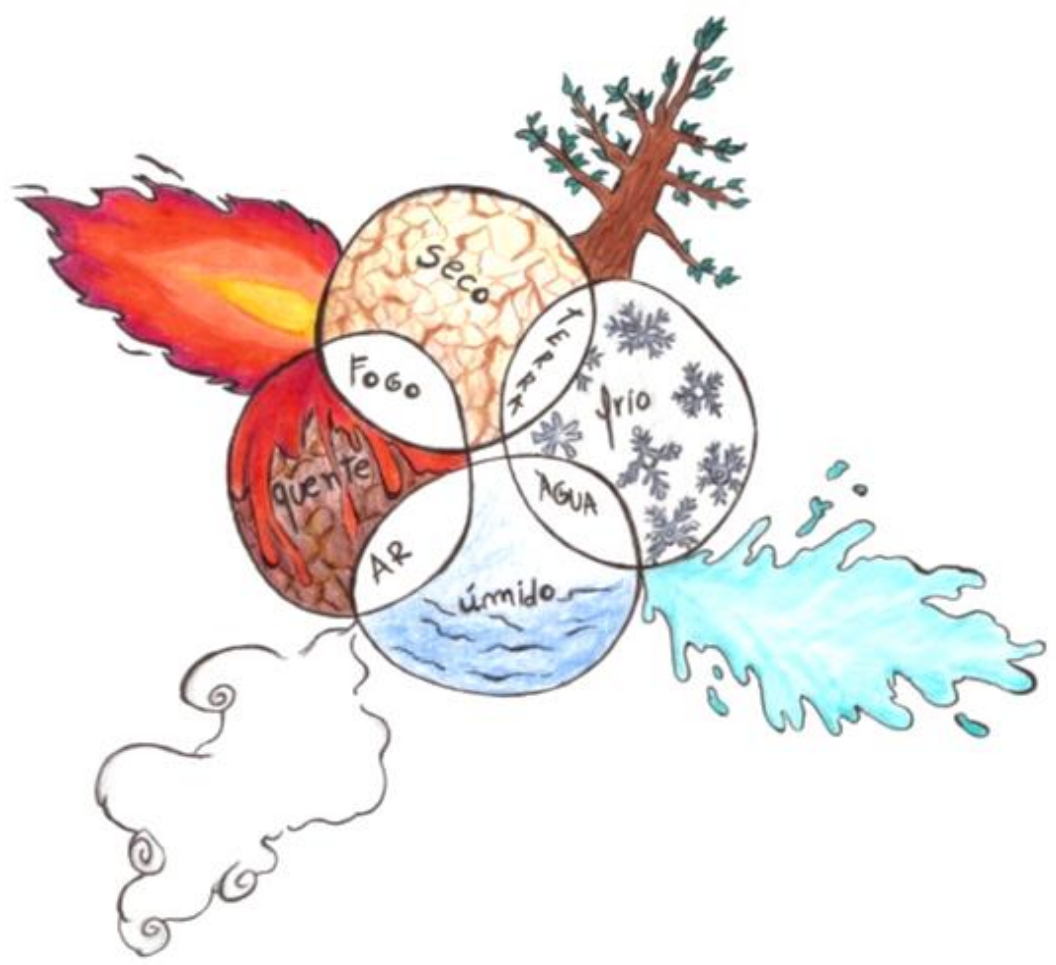

Figura 1- Representação do pensamento de Aristóteles sobre a formação da matéria (Fonte: Próprio autor)

O pensamento sobre a formação da matéria de Empédocles e, posteriormente, aperfeiçoado por Aristóteles, influenciou a interpretação de como a matéria é formada ao longo de vários séculos após a sua elaboração. Essa ideia foi também responsável pelo surgimento da alquimia ao longo da Idade Média, entre os séculos I e XV d.C., a qual tentava várias combinações de metais para a obtenção de ouro, pois partiam do princípio de que se todos eles eram formados pelos mesmos elementos, então bastaria conseguir alterar as quantidades de cada um deles dentro da matéria para obter ouro (ASIMOV, 1965; PEDUZZI, 2005). Isso levou aos alquimistas acabarem por incorporar alguns aspectos místicos nas suas práticas, já que pensaram poder fazer um material que se encarregasse de transmutar qualquer metal em ouro, a pedra filosofal.

Outro ponto que também acreditavam ser possível conseguir a partir dos princípios elaborados por Empédocles, era o elixir da longa vida ou elixir da vida eterna, o qual tornaria o homem que o bebesse imortal (PARTINGTON, 1960). Pode-se considerá-los os primeiros a tentar uma explicação fundamentada na experimentação para a explicação da matéria. O conceito onde a matéria é formada por elementos e pelas propriedades que os caracterizam, foram aceitas e utilizadas até o século XVII d.C.

A ideia de que matéria é formada por partículas indivisíveis, foi contemporânea ao pensamento elaborado por Empédocles. Por volta de 400 a.C. os filósofos gregos Leucipo e Revista Ifes Ciência, v.4, n.2, 2018 - Instituto Federal do Espírito Santo 
Demócrito elaboraram uma filosofia atômica na qual a matéria era formada por partículas indivisíveis chamada de átomos (não divisível) introduzindo a ideia de matéria descontinuada, pois, segundo eles, a matéria poderia ser dividida incessantemente até que chegaria em um ponto o qual não haveria mais como ser particionada, porque ela atingiria uma unidade indivisível (ASIMOV, 1965; PEDUZZI, 2005).

Ainda, segundo suas ideias, todas as coisas seriam formadas de átomos e vazio (vácuo) e não poderiam ser vistas, sendo eles perpétuos e idênticos em sua composição, possuindo variação no seu tamanho e forma (CARUSO e OGURI, 1996). As propriedades dos corpos seriam explicadas através da diferença dos movimentos, tamanho e forma desses átomos. Demócrito afirmou que todas as coisas eram formadas por átomos, inclusive a alma, e pela união temporária entre eles. Contudo a ideia não foi bem aceita na época (LOURENÇÃO, 2013; DIOGO, 2016).

Os estudos realizados por Lavoisier e Proust e as suas leis ponderais, influenciaram o pensamento sobre a matéria. O químico francês Antoine Laurent Lavoisier (1743-1794), conhecido como o pai da química, introduziu e aprimorou o uso da balança em pesquisas científicas, o que permitiu que ele chegasse a resultados com precisões os quais outros cientistas ainda não haviam conseguido chegar. Com isso ele elaborou o Princípio da Conservação de Massas, onde em uma reação química as massas dos reagentes, somadas, deveriam ser iguais as massas dos produtos, concluindo assim que não há perda nem ganho de matéria, apenas uma reorganização dos elementos que formariam compostos novos. Joseph Louis Proust (1754-1826), químico francês, observou que em uma reação química a relação entre as massas das substâncias participantes é sempre constante, isso permitiu com que ele elaborasse a Lei das Proporções Definidas. Segundo ele a proporção das massas dos elementos presentes nos reagentes se mantem nos produtos e ao ocorrer uma variação nos valores das massas dos reagentes, as massas dos produtos irão variar proporcionalmente. As suas ideias influenciaram o pensamento de Dalton na elaboração do seu modelo atômico (PARTINGTON, 1960; ASIMOV, 1965; CARUSO e OGURI, 1996).

Entre 1803 e 1808, John Dalton (1766-1844) (Figura 2) elabora e propõe a sua teoria sobre a estrutura pela qual a matéria é constituída. Ele retoma o pensamento elaborado outrora por Demócrito e Leucipo e visando justificar os resultados obtidos por Lavoisier e Proust, elabora o seu modelo (PEDUZZI, 2005). Logo ele estabeleceu postulados os quais a sua teoria era firmada. 


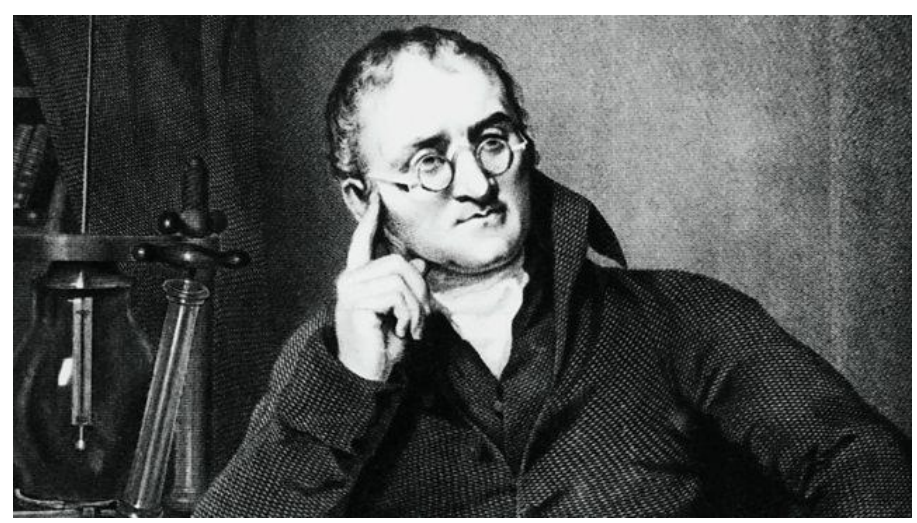

Figura 2 - Jonh Dalton (Fonte: https://www.bbc.co.uk/programmes/b07zzy8b)

O primeiro postulado dizia que toda a matéria seria formada por minúsculas partículas, denominadas átomos, sendo que eles não poderiam ser criados e nem destruídos, sendo cada substância constituída de um único tipo de átomo. O segundo postulado dizia que substâncias simples são formadas por átomos simples, sendo esses átomos isolados, porque átomos do mesmo elemento sofreriam repulsão e átomos simples seriam indivisíveis. O terceiro aborda que substâncias compostas seriam formadas por átomos compostos possuindo capacidade de se decomporem, através de uma reação química, em átomos simples. O quarto e último postulado dizia que átomos de uma mesma substância são idênticos em tamanho, forma e demais propriedades e átomos de substâncias diferentes possuem essas propriedades diferentes uns dos outros, sendo que a massa de um átomo composto é igual a somas dos átomos simples que o formam (TAVARES, 2007; PEDUZZI, 2005).

Sendo a definição de postulados como afirmações que não podem ser comprovadas, porém são assumidas como verdade para que se possa fazer conclusões, os postulados elaborados por Dalton definiram que toda a matéria é constituída por átomos; foi atribuída a forma esférica, e seriam maciços e indivisíveis (Figura 3); um grupo de átomos, que possui propriedades iguais, formam um elemento químico, que apresenta diferentes propriedades físicas e químicas em relação a todos os demais elementos; a formação de materiais se dá a partir da união de átomos diferentes originando assim as moléculas, que ele chama de átomos compostos, os quais não surgem ou desaparecem, apenas se reorganizam quando submetidos a uma reação química (PARTINGTON, 1960; MACEDO e CARVALHO, 2000). 


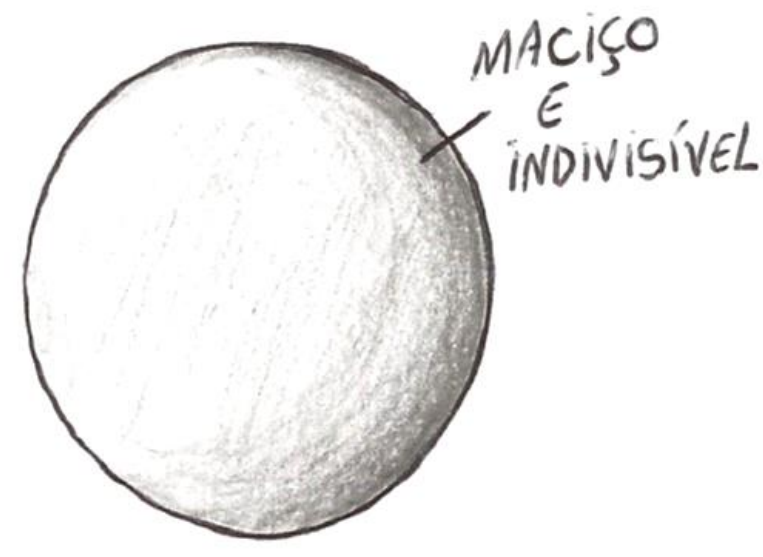

Figura 3 - Modelo Atômico proposto por Dalton (Fonte: Próprio autor).

$\mathrm{Na}$ época da elaboração do modelo atômico de Dalton haviam sido identificados cerca de 50 elementos diferentes (CARUSO e SANTORO, 1994). Com o objetivo de melhorar a representação simbólica, Dalton propôs novos símbolos utilizando pequenos círculos, com representações no seu interior, para os elementos que os alquimistas ainda não conheciam e substituiu os antigos por novos. Por volta de 1810 o químico sueco Jöns Jakob Berzelius (1779-1848) organizou a notação química dos elementos introduzindo como seus símbolos letras que representavam seus nomes em latim, pois a notação naquela época era bastante confusa. Para indicar a proporção do elemento químico na molécula, ele associou um número ao símbolo do elemento em questão para indicar a sua quantidade, sendo que esse número ele chamou de índice, contudo quando a apenas um único átomo de um elemento na molécula, não há representação por número (PARTINGTON, 1960; ASIMOV, 1965; PEDUZZI, 2005).

Contudo o modelo de Dalton ainda era insuficiente para entender e explicar certos fenômenos como uma propriedade importante da matéria, a natureza elétrica. Essa propriedade já era conhecida por Tales de Mileto no século V a.C., na Grécia antiga, onde ao esfregar lã de carneiro em um pedaço de âmbar, que em grego chama-se elektron, ele percebeu que ela começava a atrair algumas folhas secas para próximo de si (PARTINGTON, 1960; PEDUZZI, 2005).

Outro que passou a observar a propriedade elétrica da matéria foi o físico norte-americano Benjamin Franklin (1706-1790), que constatou a existência de cargas as quais ele nomeou de positiva e negativa. Sua observação foi feita com base no fato de que dois materiais ao serem atritados, adquiriam cargas opostas resultando em atração, logo ele concluiu que materiais que possuem a mesma carga se repelem e que possuem cargas diferentes sofrem atração mutua (ASIMOV, 1965). Mediante a essas questões mostrou-se necessário um modelo que explicasse tal fenômeno. 


\section{O MODELO DE THOMSON}

Em 1897 o cientista inglês Joseph John Thomson (1856-1940) (Figura 3), estudou o comportamento de gases mediante a uma descarga elétrica em um experimento com tubos de raios catódicos (Figura 4), que consiste em um tubo de vidro onde são acoplados dois eletrodos, um cátodo e um anodo ligados a um gerador de voltagem variável, e uma bomba de vácuo ligada ao sistema (THOMSON, 1897; PARTINGTON, 1960; CARUSO e OGURI, 1996).

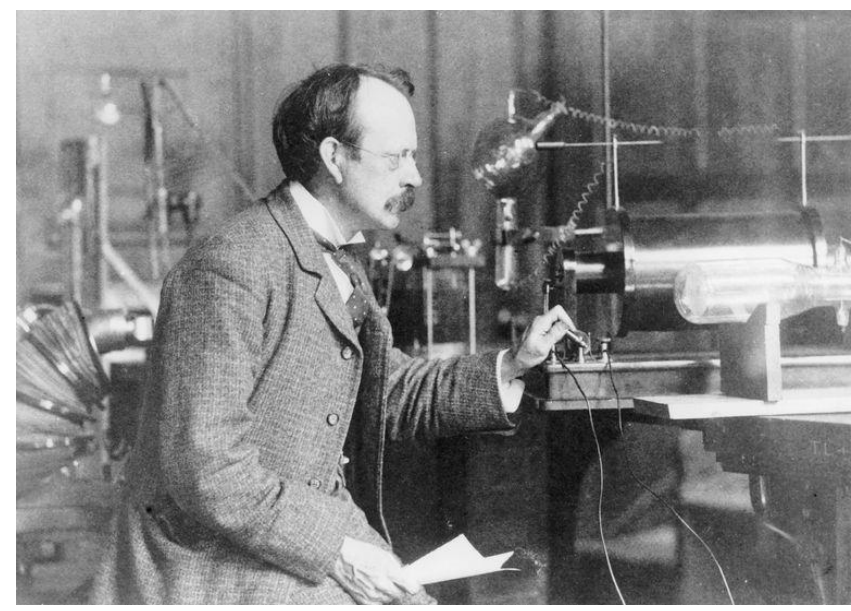

Figura 3 - Joseph John Thomson (Fonte: https://www.thoughtco.com/j-j-thomsonbiography-607780)

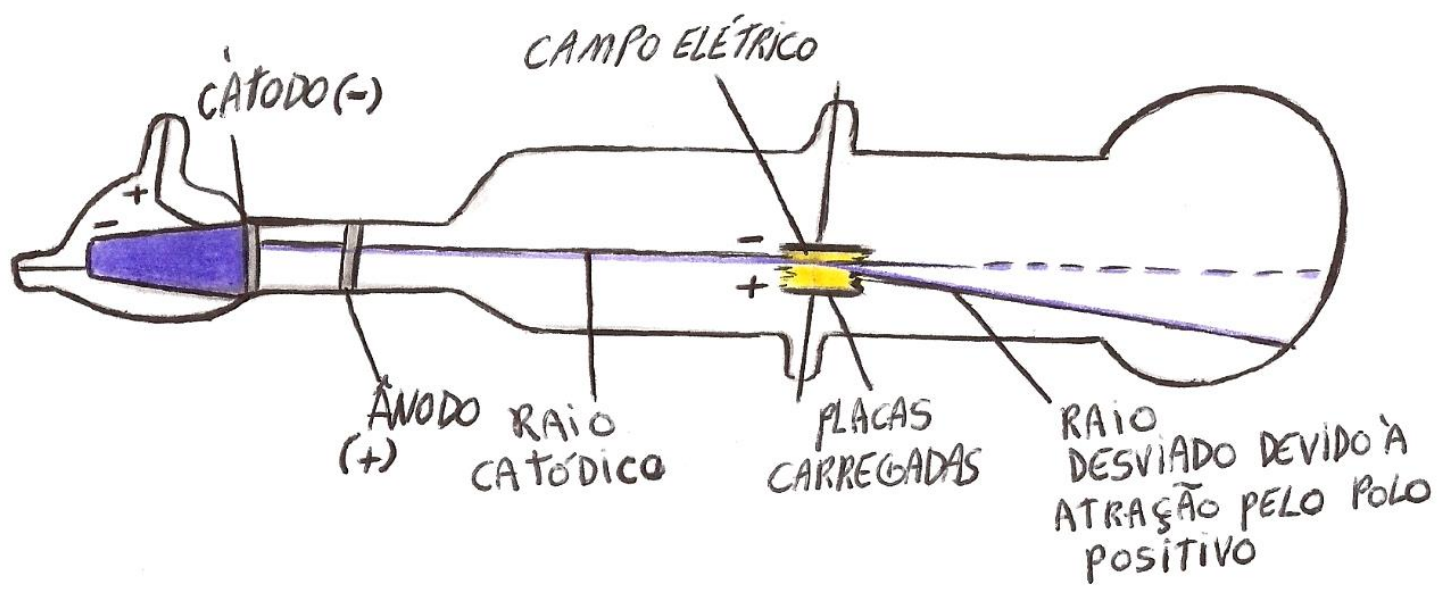

Figura 4 - Tubo de raios catódicos de Thomson (Fonte: Próprio autor).

Ao realizar o experimento coloca-se um gás no interior do tubo de vidro e retira-se uma grande parte dele com o uso da bomba de vácuo, o que gera uma luminosidade no interior do tubo, que parte do cátodo para o ânodo, provocando uma fluorescência na parede de vidro do tubo que estava oposta Revista Ifes Ciência, v.4, n.2, 2018 - Instituto Federal do Espírito Santo 
do cátodo (THOMSON, 1897; HARTWIG, et. al., 1999). No ano de 1878, anteriormente a Thomson, William Crookes (1822-1919) realizou um aperfeiçoamento do tubo de raios catódicos colocando o polo positivo ao lado do negativo. Esse sistema foi chamado de ampola de Crookes (Figura 5) onde ele estabeleceu algumas propriedades aos raios catódicos como o fato de eles serem retilíneos, o que ele observou através da sombra que se formava em um anteparo do lado oposto do cátodo; que eles possuem massa, observou isso após colocar um molinete na trajetória dos raios notando que ele se movimentava; e que possuía carga negativa, devido ao desvio que sofriam na direção da placa que possuía carga positiva (PARTINGTON, 1960; LOPES 2009).

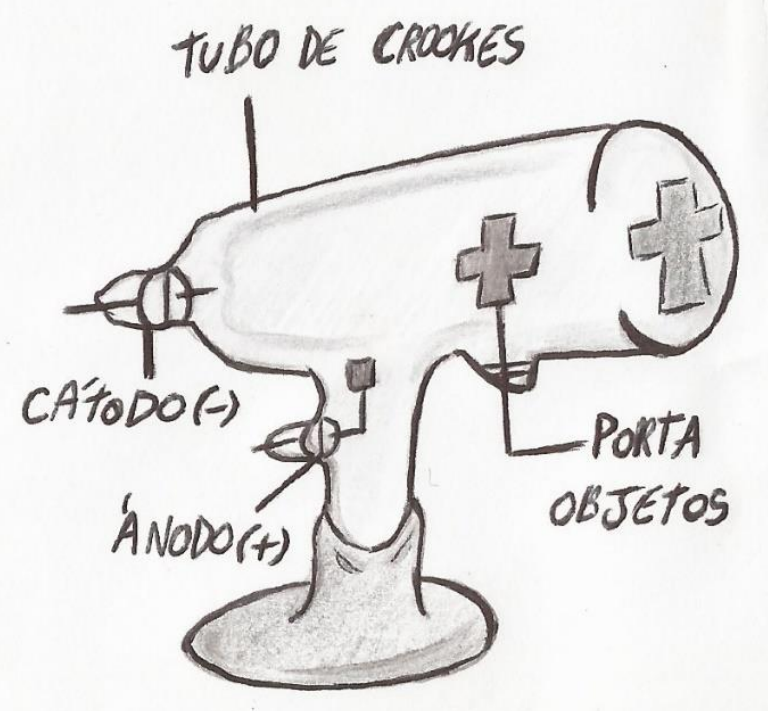

Figura 5 - Ampola de Crookes (Fonte: Próprio autor)

Logo Thomson, em colaboração com Rutherford, conseguiu, através do seu experimento, estabelecer uma relação entre carga e massa das partículas presentes nos raios catódicos e notando que ela era constante, concluindo então que elas estavam presentes em qualquer tipo de matéria e nomeio as partículas de elétron, através de uma sugestão do cientista irlandês George Johnstone Stoney (1826-1911) (LOPES, 2009).

Ele também chegou a outras conclusões de que o fato das cargas positivas, como os raios canal e as partículas alpha, tinham uma massa maior que a dos elétrons, concluindo que maior parte do átomo era formado por partículas positivas; que a matéria era eletricamente neutra, e os elétrons eram negativos, logo o átomo deveria ter um equivalente positivo para que ele se mantivesse neutro; que a matéria pode adquirir carga elétrica. Logo, isso leva a crer que os elétrons não estão fixos de forma inseparável ao átomo, sendo que, mediante a certas circunstâncias eles podem ser transferidos de um átomo para o outro e que eles não seriam maciços e indivisíveis, devido a radioatividade (PARTINGTON, 1960).

Revista Ifes Ciência, v.4, n.2, 2018 - Instituto Federal do Espírito Santo 
Com isso ele descreveu o átomo como não sendo maciço e indivisível, mas esférico com carga positiva o qual possuía na sua superfície partículas, em movimento, com cargas negativas, os elétrons (THOMSON, 1904; HALLIDAY, et. al., 2008), sendo que ele próprio associou o seu modelo (Figura 5) a um pudim de passas no seu trabalho de 1897 onde ele apresentou o seu modelo, explicando fenômenos que não eram possíveis de ser compreendidos através do modelo de Dalton (PEDUZZI, 2005).

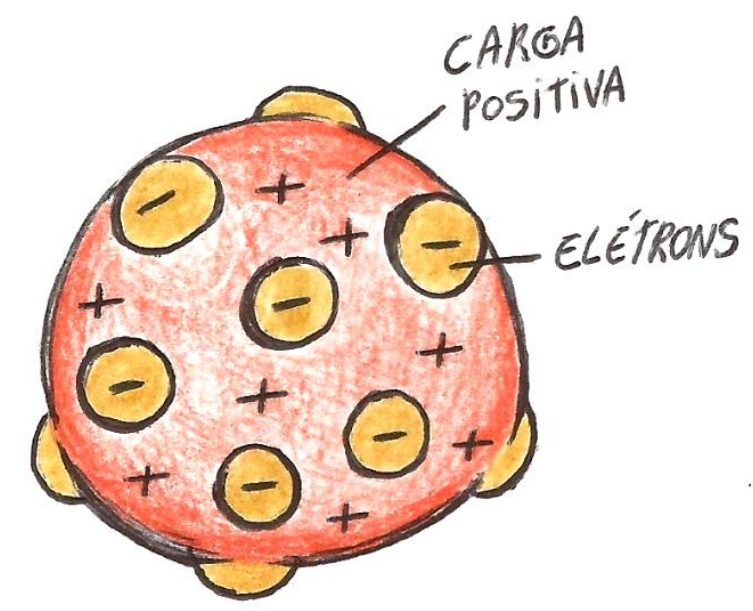

Figura 5 - Modelo atômico de Thomson (Fonte: Próprio autor)

A radioatividade foi um dos acontecimentos mais importantes que contribuíram para o estudo e desvendamentos das estruturas atômicas. Seu registro científico é em decorrência da observação de Antoine Henri Becquerel (1852-1908), da ação de raios com grande poder de penetração emitidos pelo sal de urânio quando estes ficaram próximos a uma placa fotográfica (PARTINGTON, 1960; PEDUZZI, 2005).

Os estudos sobre os raios canais também contribuíram de forma significativa para o entendimento do átomo. Foram assim denominados pelo físico alemão Eugen Goldstein (1850-1930), em 1886, quando ele usou um tubo de raios catódicos modificado onde o cátodo era uma placa de metal perfurada (PEDUZZI, 2005). Concomitantemente, Marie Currie (1867-1934) decidiu estudar o fenômeno da radioatividade junto com seu marido Pierre Curie (1859-1906), eles analisaram a emissão de raios capazes de impressionar filmes fotográficos e tornar o ar condutor de eletricidade, isso seria uma prerrogativa do urânio, o que culminou na descoberta os elementos químicos rádio e polônio, em 1898, onde ela sugeriu a instabilidade desses elementos. (CURIE, 2012; PARTINGTON, 1960).

A massa dos raios canais é maior que a dos catódicos, podendo variar conforme o gás utilizado, sendo que os provenientes do hidrogênio possuem a menor massa obtida (SALMERON, 2007). Esse tipo de tubo contribuiu e permitiu a identificação do próton por Rutherford, quando ele Revista Ifes Ciência, v.4, n.2, 2018 - Instituto Federal do Espírito Santo 
aprimorou os experimentos de Goldstein, juntamente com o físico inglês James Chadwick (18911974), eles o isolaram pela primeira vez em 1922, descobrindo que sua massa era 1826 vezes maior que a do elétron (PARTINGTON, 1960).

\section{O MODELO ATÔMICO DE RUTHERFORD E BOHR}

Em 1911 o físico neozelandês Ernest Rutherford (1871-1937) (Figura 6) desenvolveu um experimento onde procurava observar o interior do átomo através de um padrão pelo qual as partículas alfa se desviariam, visando assim a comprovação e adequação do modelo de Thomson, que era orientador. $\mathrm{O}$ experimento constituía em direcionar o percurso das partículas alfa para uma colisão com uma placa de ouro de espessura de $10^{-4} \mathrm{~mm}$ (Figura 7) (RUTHERFORD, 1911; PARTINGTON, 1960; ASIMOV, 1965; MARQUES E CALUZI, 2003; PEDUZZI, 2005; LOPES, 2009).

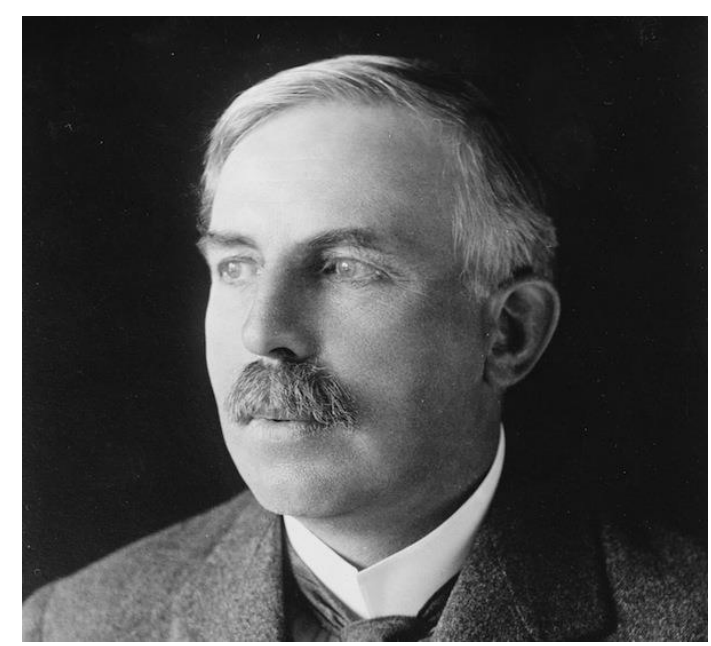

Figura 6 - Ernest Rutherford (Fonte: https://seuhistory.com/hoje-na-historia/morre-ernestrutherford-o-pai-da-fisica-nuclear) 


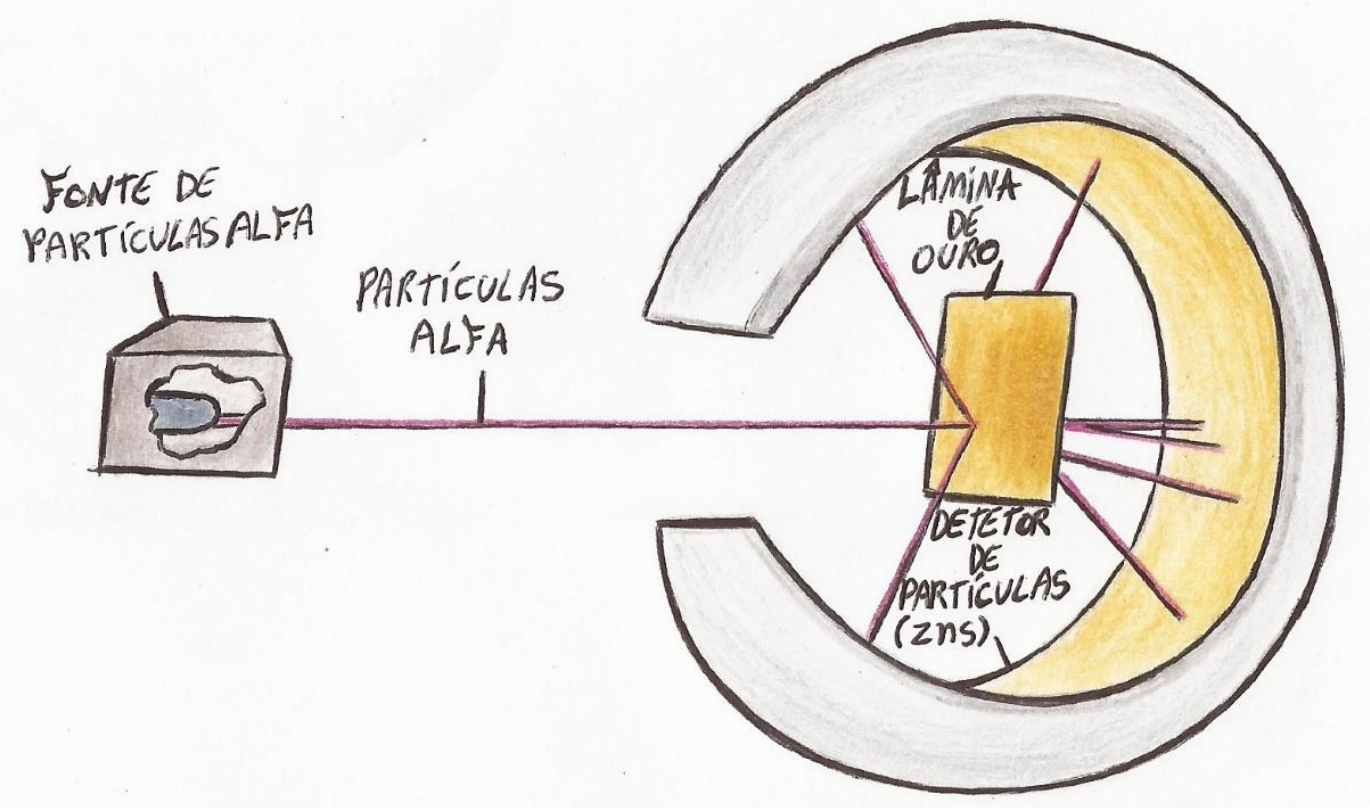

Figura 7 - Experimento de Rutherford (Fonte: Próprio autor)

O ouro foi o material escolhido por ser pouco reativo. $\mathrm{O}$ resultado esperado era que as partículas alfa atravessassem o ouro de uma forma como um tiro de espingarda atravessaria uma folha de papel, de forma direta e sem ricochetear. O experimento foi montado colocando uma amostra de polônio no interior de uma cavidade funda em um bloco de chumbo através de um pequeno orifício, pois as partículas alfa não conseguem atravessar o chumbo, passando apenas pelo orifício por onde a amostra de polônio foi colocada. Em frente a essa caixa foram colocadas mais algumas placas de chumbo com o objetivo de conseguir orientar as partículas alfa de encontro a placa de ouro, sendo que ao redor dessa placa foi colocado um anteparo coberto por sulfeto de zinco ( $\mathrm{ZnS})$ o qual permitia visualizar o trajeto. Rutherford e os outros cientistas que trabalharam com ele, como o físico alemão Johannes Wilhelm Geiger (1882-1945) e o físico inglês Ernest Marsden (1889-1970) (PEDUZZI, 2005; HALLIDAY, et. al., 2008), variaram a posição do anteparo em volta da placa para poderem realizar mais observações e notaram que haviam pontos luminosos em diversos ângulos, alguns variando até $180^{\circ}$ (LOPES, 2009). Isso demonstrou que algumas partículas colidiram com "objetos" densos presentes ali, observando que a maioria das partículas alfa atravessavam a placa de ouro livremente, algumas delas sofriam desvio e pouquíssimas pareciam não atravessar (GEIGER E MARSDEN, 1913).

Ruhterford (1911), aborda sobre a deflexão de partículas no seu trabalho, onde diz:

Um cálculo simples baseado na teoria da probabilidade mostra que a chance de uma partícula $\alpha$ sendo defletidas por $90^{\circ}$ é muito pequena. Além disso, será visto mais tarde que a distribuição das partículas $\alpha$ por vários ângulos de grande desvio, não segue a lei da probabilidade como o esperado, se uma deflexão tão grande for composta de um grande 
número de pequenos desvios. Parece razoável supor que a deflexão através de um grande ângulo é devido ao encontro com um único átomo e a chance de um segundo encontro produzir um tipo de grande deflexão precisa, na maioria dos casos, ser extremamente pequena.

Os resultados obtidos mostraram que a placa de ouro funcionava como uma "peneira" onde a sua massa estaria distribuída de forma não uniforme. Esse fenômeno causou estranheza, pois seguindo o modelo elaborado por Thomson o átomo seria homogêneo e as partículas não sofreriam grandes desvios (PARTINGTON, 1960; LOPES, 2009). Rutherford inclusive declarou que isso tinha sido uma das coisas mais incríveis que tinha acontecido na vida dele, concluindo que era como se disparasse uma bala de canhão em uma folha de papel e a bala ricocheteasse (HALLIDAY, et. al., 2008).

Com os resultados, Rutherford apresentou uma alteração no modelo atômico sendo o átomo constituído de espaços vazios, possuindo em seu centro um núcleo pequeno e denso. Devido a repulsão sofrida pelas partículas alfa, que possuem carga positiva, ao se aproximarem do núcleo, atribuiu-se uma carga positiva ao núcleo; a carga positiva era equilibrada pelos elétrons, que detém carga negativa, e estariam localizados em uma região periférica denominada eletrosfera (BOHR, 1913a; MARQUES E CALUZI, 2003). Ele concluiu que a massa da lâmina de ouro estaria concentrada em pequenos pontos, que seria o núcleo. A lógica do núcleo positivo e da eletrosfera negativa justificavam a natureza neutra do átomo. Com isso notou-se que um novo modelo deveria ser descrito para explicar os resultados. Então, em fevereiro de 1911, Rutherford defendeu a sua tese sobre o assunto intitulada de "Da dispersão das partículas alfa e beta pela matéria e da estrutura do átomo" que culminou para a elaboração um novo modelo atômico (MARQUES E CALUZI, 2003).

As suas experiências o levaram a concluir também que o núcleo era muito maior em massa que a eletrosfera e que para os prótons não sofrerem repulsão, o núcleo deveria possuir uma partícula sem carga de massa igual ao próton. Sendo que, em 1932, James Chadwick provou a existência das tais partículas sem carga e nomeou-as de nêutrons (HALLIDAY, et. al., 2008).

Após essa descoberta definiu-se as cargas das partículas que formariam o átomo sendo os prótons com carga positiva e os nêutrons com carga neutra, possuindo a mesma massa dos prótons, sendo essas duas partículas responsáveis pela formação do núcleo do átomo e os elétrons que possuem carga negativa, localizados em uma eletrosfera que circunda o núcleo possuindo uma massa muito menor que a dos prótons e nêutrons (PARTINGTON, 1960). O modelo de Rutherford, possui uma aparência semelhante a um minúsculo sistema planetário, isso levou ele a ser conhecido como "Modelo Sistema Solar" ou "Modelo Planetário" (Figura 8) (LOPES, 2009). 


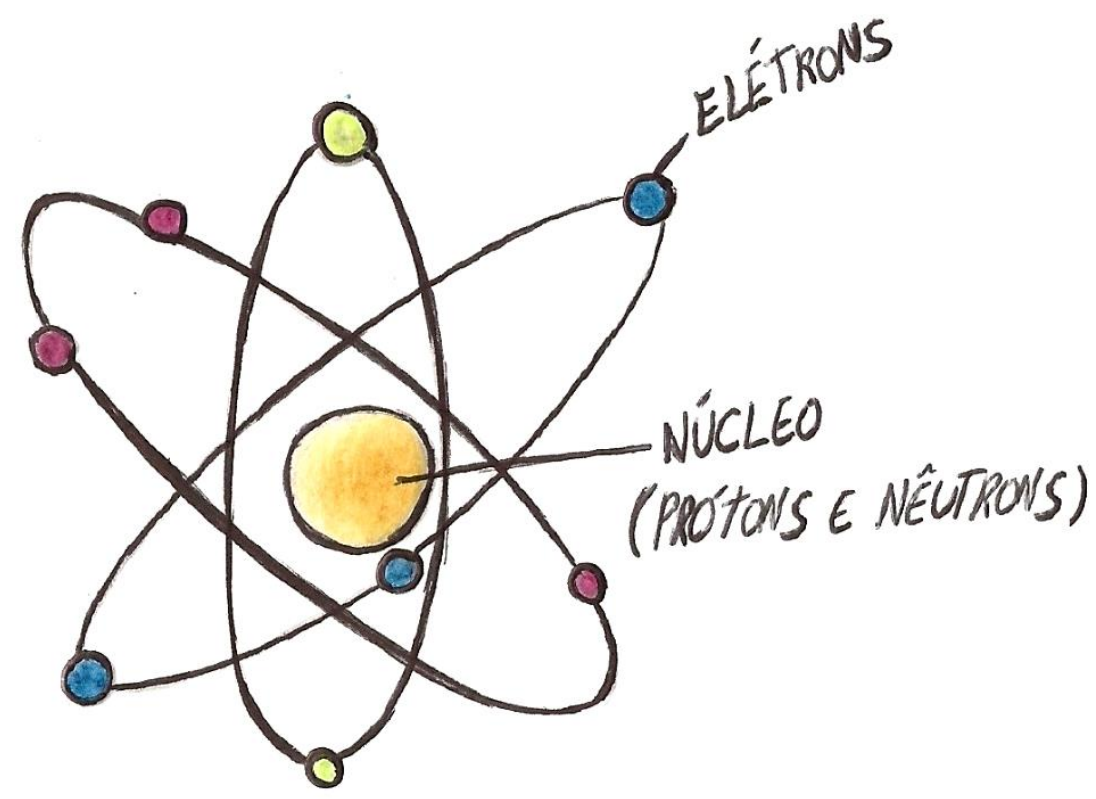

Figura 8 - Modelo atômico proposto por Rutherford (Fonte: Próprio autor)

Em um de seus trabalhos, Rutherford (1920), ao fazer definições sobre o átomo, diz:

Esse núcleo carregado positivamente contém a maior parte da massa do átomo e é circundado à distância por uma distribuição de elétrons negativos em número igual à carga positiva resultante no núcleo. Sob essas condições, existe um campo elétrico muito intenso próximo ao núcleo, e a grande deflexão da partícula alfa em um encontro com um único átomo acontece quando a partícula passa perto do núcleo. Assumindo que as forças elétricas entre a $\alpha$-partícula e o núcleo variavam de acordo com uma lei do quadrado inverso na região próxima ao núcleo, o escritor elaborou as relações que conectam o número de partículas $\alpha$ espalhadas por qualquer ângulo com a carga sobre o núcleo e a energia da partícula $\alpha$. Sob o campo de força central, a $\alpha$-partícula descreve uma órbita hiperbólica em volta do núcleo, e a magnitude da deflexão depende da proximidade da aproximação do núcleo.

O modelo de Rutherford foi muito utilizado e ainda atualmente explica alguns fenômenos físicos existentes. Contudo, desde sua elaboração, apresenta algumas contradições relevantes que comprometem a sua aceitação plena. Essas questões dizem respeito ao fato de que um sistema planetário é regido pelas leis da gravidade, enquanto um sistema atômico é elétrico e as leis regentes desses dois sistemas são diferentes. Outro ponto seria o fato de as partículas de cargas opostas sofrerem atração e os elétrons deveriam perder energia ao orbitarem de forma gradual percorrendo um trajeto em forma de espiral em direção ao núcleo, e conforme fossem perdendo essa energia à emitiriam em forma de luz (LOPES, 2009).

Para entender a natureza dos elétrons presentes no modelo de Rutherford, o cientista dinamarquês Niels Bohr (1885-1962) (Figura 9) procurou explicá-los através dos subsídios que seus experimentos com espectro atômicos lhe deram. Sua teoria foi elaborada sobre o movimento e disposição dos elétrons no átomo. Ele concluiu que se os átomos só emitem radiações em certos Revista Ifes Ciência, v.4, n.2, 2018 - Instituto Federal do Espírito Santo 
comprimentos de onda e em certas frequências determinadas, então os átomos se apresentam em estados de energia bem determinados também (Figura 10). Com isso Bohr elaborou postulados que permitiram o entendimento dessa natureza (PEDUZZI, 2005).

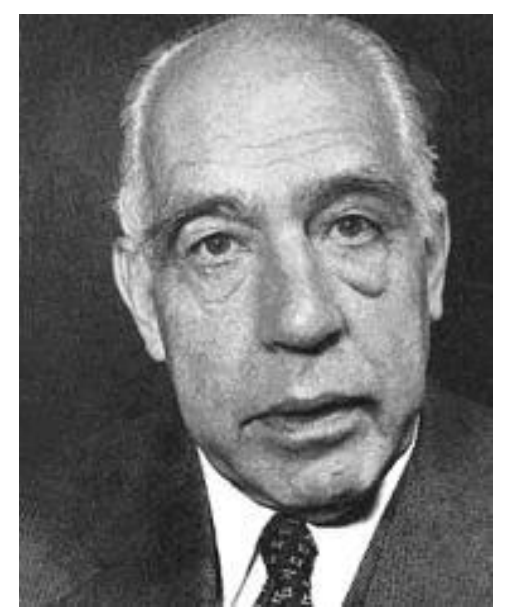

Figura 9 - Niels Bohr (Fonte:

http://www.fiocruz.br/biosseguranca/Bis/Biograf/ilustres/niels.htm)

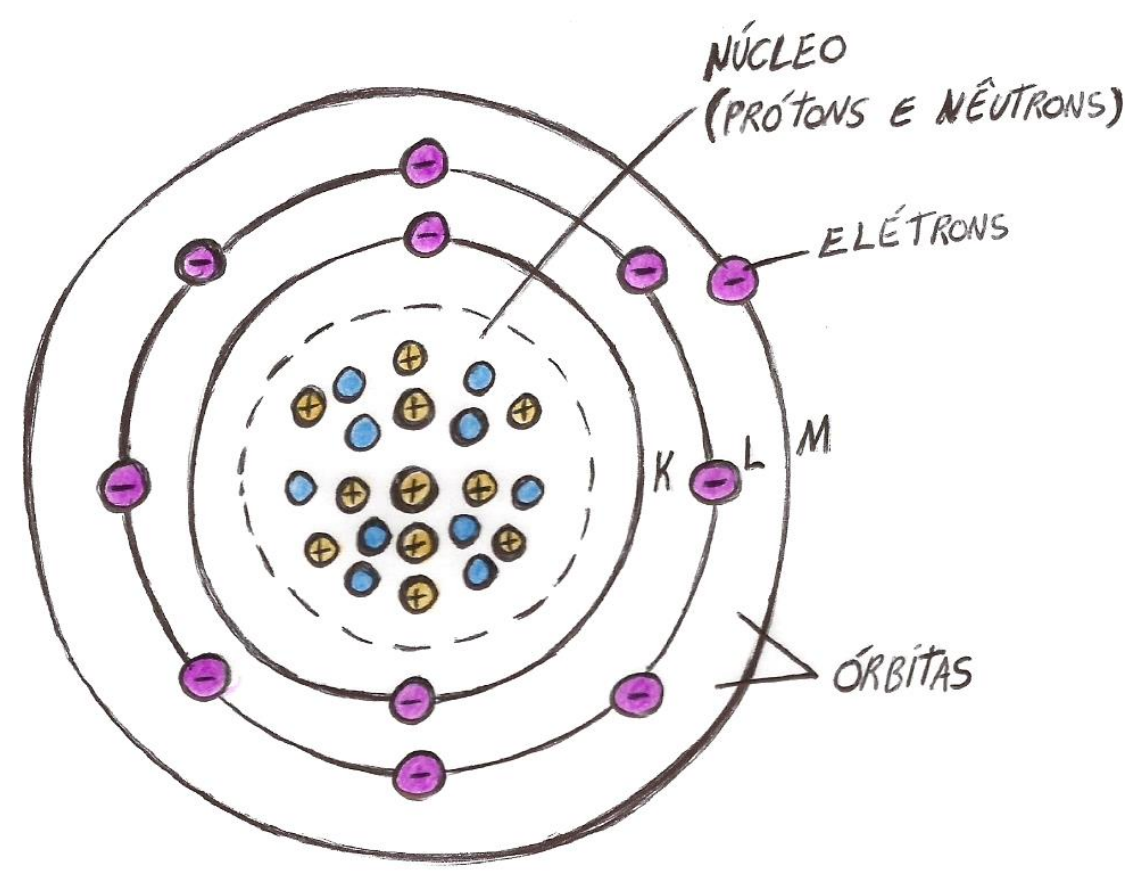

Figura 10 - Modelo atômico proposto por Niels Bohr a partir do modelo de Rutherford (Fonte: Próprio autor)

O primeiro deles diz que os elétrons descrevem uma órbita circular ao redor do núcleo com energia fixa e determinada, sendo chamadas elas de órbitas estacionárias, onde o impulso angular de cada elétron, em torno do centro de sua órbita, é igual ao valor universal $h / 2 \pi$, onde $h$ é a constante Revista Ifes Ciência, v.4, n.2, 2018 - Instituto Federal do Espírito Santo 
de Planck. O segundo diz que os elétrons não emitem energia enquanto se movimentam nessas órbitas. O terceiro postulado diz que quando ele recebe energia suficiente ele salta para outra órbita, sendo que, após receber essa energia, ele tende a voltar para a sua órbita original emitindo essa energia de volta, podendo essa emissão ser em forma de luz ou calor, chamado fótons, sendo que a energia devolvida e recebida é igual a diferença das energias das duas órbitas, onde temos:

$$
E_{f}-E_{i}=h v
$$

Sendo $E_{f}$ a energia do estado final do elétron e $E_{i}$ a energia no seu estado inicial, $h$ a constante de Plank e $v$ a velocidade da luz. (BOHR, 1913b; PARTINGTON, 1960; MACEDO E CARVALHO, 2000).

Contudo as conclusões de Bohr não satisfazem por completo o entendimento do átomo, pois ele explica de forma satisfatória o átomo de hidrogênio, onde as energias correspondentes de cada uma das órbitas, encaixavam-se em:

$$
E=\frac{R_{h}}{n^{2}}
$$

Onde a energia $(E)$ é dada pelo quociente de $R_{h}$, constante no valor de $-2,179 \times 10^{-18} \mathrm{~J}$, e $n$ que seria o número quântico. Contudo, isso não se aplica aos outros átomos, além de não explicar por qual motivo o elétron apresenta energia constante além de possuir a restrição de que os elétrons nem sempre apresentam uma órbita circular ou elíptica ao redor do núcleo (LOPES, 2009).

\section{CONSIDERAÇÕES FINAIS}

Ao longo da história da ciência, procura pela compreensão do que é formada a matéria se confunde com a do mundo natural, passando pelas várias etapas da evolução do conhecimento humano, aumentando sua complexidade.

No início do pensamento humano, a composição da matéria foi desenvolvida a partir de duas linhas pensamentos pautados em observações do mundo natural e conclusões filosóficas, sendo que, em seguida, com o surgimento da alquimia, foram atribuídas propriedades místicas a matéria, reforçando a ideia de que a mesma seria elemental. Contudo, com a sistematização da experimentação 
e do rigor cientifico utilizando instrumentos de medida, como a balança, introduzida por Lavoisier, pode-se obter resultados mais precisos, que se mostrou determinante para que houvessem comprovações de teorias e explicações concisas.

Os postulados elaborados por Dalton, a partir da retomada do pensamento de Demócrito e Leucipo, onde a matéria seria particulada, foi fundamental, pois deu início a uma série de acontecimentos que foram determinantes para que esse campo fosse explorado e discutido.

O experimento de Thomson foi o primeiro chegar a uma conclusão mais complexa da ideia do que seria formada a matéria, onde ele percebeu que essa partícula, descrita pelos postulados de Dalton, possuiria uma carga. Em seguida, o experimento de Rutherford, junto com os postulados elaborados por Bohr, chegaram a um modelo que explicaria de uma forma mais precisa de como a matéria seria formada.

A história da composição da matéria está ligada diretamente com a história da ciência e com a evolução do pensamento científico, sendo observada uma constante modificação e aprimoramento de ideias que se sucedem aumentando sua complexidade conforme o avanço que acontece no campo da experimentação, chegando a estrutura atômica como modelo que melhor explica o comportamento da matéria, contudo várias descobertas ainda tem sido feitas, mostrando que há um longo caminho até que se entenda a total composição da matéria.

\section{REFERÊNCIAS}

ASIMOV, Isaac. A short history of chemistry. New York: Doubleday, 1965. 263 p.

BOHR, Niels. II. On the theory of the decrease of velocity of moving electrified particles on passing through matter. The London, Edinburgh, and Dublin Philosophical Magazine and Journal of Science, v. 25, n. 145, p. 10-31, 1913a.

BOHR, Niels. On the Constitution of Atoms and Molecules. Part II: Systems containing only a Single Nucleus. Coleção de artigos para o complexo multimídia e-learning e metodológico sobre o tema "Física do átomo e dos fenómenos atómicos"; BSU, Faculdade de Física, 1913b.

CARUSO, Francisco; SANTORO, Alberto. Do átomo Grego à Física das interações fundamentais. Rio de Janeiro: AIAFEX, 1994.

CARUSO, Francisco; OGURI, Vitor. A eterna busca do indivisível: do átomo filosófico aos quarks e léptons. Química Nova, v. 20, n. 3, p. 324-334, 1997. 
CURIE, Marie. Pierre Curie: With Autobiographical Notes by Marie Curie. $2^{\mathrm{a}}$. New York: Dover Publications, 2012.

DIOGO, João Emanuel. Atomismo ético de Leucipo e Demócrito. Boletim de Estudos Clássicos, n. 61 , p. 67-84, 2016.

GEIGER, Hans; MARSDEN, Ernest. The laws of deflexion of a particles through large angles. The London, Edinburgh, and Dublin Philosophical Magazine and Journal of Science, v. 25, n. 148, p. 604-623, 1913.

HALLIDAY, David. RESNICK, Robert. WALKER, Jearl. Fundamentos da física volume 4: óptica e física moderna. Rio de Janeiro, LTC, 2008.

HARTWIG, Dalcio Rodney. SOUZA, Edson de. MOTA, Ronaldo Nascimento Química: geral e inorgânica. São Paulo: Scipione, 1999.

LOPES, Cesar Valmor Machado. Modelos atômicos no início do século XX: da física clássica à introdução da teoria quântica. São Paulo: PUC 2009.

LOURENÇÃO, Rayra F. et al. A Alquimia e a Química: História e Contribuições. Secretaria de Estado da Educação-SP Diretoria de Ensino de Piracicaba, P. 26, 2013.

MACEDO, Magno Urbano de. CARVALHO, Antônio. Química. São Paulo: IBEP, 2000.

MARQUES, Deividi Marcio; CALUZI, João José. Ensino de Química e História da Ciência: O Modelo Atômico de Rutherford. $4^{\text {a }}$ ENCONTRO NACIONAL DE PESQUISA EM EDUCAÇÃO EM CIENCIAS-ABRAPEC, Bauru, 2003.

PARTINGTON, James Riddick. A short history of chemistry. Courier Corporation, 1960.

PEDUZZI, Luiz OQ. Do átomo grego ao átomo de Bohr. Florianópolis: Departamento de Física/UFSC, 2005

RUTHERFORD, Ernest. LXXIX. The scattering of $\alpha$ and $\beta$ particles by matter and the structure of the atom. The London, Edinburgh, and Dublin Philosophical Magazine and Journal of Science, v. 21, n. 125 , p. 669-688, 1911.

RUTHERFORD, Ernest. Bakerian lecture: nuclear constitution of atoms. Proc. R. Soc. Lond. A, v. 97, n. 686, p. 374-400, 1920. 
SALMERON, Roberto Aureliano. Física moderna. São Paulo: e-Física, Ensino de Física On-Line, 2007. Disponível em : < http://efisica.if.usp.br/moderna/conducao-gas/cap1_09/> Acessado em 28 nov 2018

THOMSON, Joseph. John. XL. Cathode rays. The London, Edinburgh, and Dublin Philosophical Magazine and Journal of Science, v. 44, n. 269, p. 293-316, 1897.

THOMSON, Joseph. John. XXIV. On the structure of the atom: an investigation of the stability and periods of oscillation of a number of corpuscles arranged at equal intervals around the circumference of a circle; with application of the results to the theory of atomic structure. The London, Edinburgh, and Dublin Philosophical Magazine and Journal of Science, v. 7, n. 39, p. 237-265, 1904. 